\title{
Foreword: Towards a Reparatory Politics of Researching Multilingually
}

\author{
Alison Phipps
}

But for educational purposes, as we have said, we must use tunes and modes too which have ethical value. (Aristotle, 1981)

The Politics of Researching Multilingually sits firmly within the western tradition of scholarship. It takes concepts such as ethics, politics and poetics which have stalked the academies of the west since Plato opened his Academy and Aristotle wrote a treatise on these very subjects. The tradition of bringing critique to bear on the politics and political economies of research endeavours and their genealogies is an important element for determining the health of a discipline or field. Multilingual methods in research to critical scrutiny is nascent in the academy, but it too relies on the long-established framings of ethics, politics and poetics.

The Politics of Researching Multilingually follows work led by Holmes et al. (2013) which highlighted critical questions of ethics and praxis in researching multilingually in the special issue of The International Journal of Applied Linguistics. In this work, the authors concluded:

Questions concerning languages in theses, publications, and examinations point to the need for the decolonisation of the linguistic imperialism of English. Policy also needs to privilege multiple languages in the writing up of research so that researchers, researched, and the communities with which the research is concerned can all access the research.

The work involved in offering critiques of the politics of researching multilingually is immense, not least as it involves discussion of language contexts ethically fraught and often linguistically remote from the traditional skills of the researcher. In particular, through its focus on multilingual communities and multilingual ideologies, this work pointed to 
the multilingual needs presenting, for instance, amongst displaced peoples and in refugee determinations. It was prescient. The research since the inception of this work on researching multilingually (published in 2013) and in intercultural studies, and also across the arts, humanities and social sciences in general, has highlighted the need for researchers to be mindful of their linguistic resources, and those of others, in their research, especially in contexts of forced migration, conflict, occupation and economic marginalisation. It is even more pressing in the current context where research focuses on the needs, real and imagined, of refugees, and refugee policy worldwide. This example demonstrates the extent to which ideological underpinnings of research practice can have real-world consequences for how a range of situations are influenced by history, politics and education. This context calls for rethinking how knowledges are constructed and in what languages. Research in the arts, humanities and social sciences has also taken a turn towards other concerns which have transnational dimensions, not least international education, climate change, indigenous knowledges and international development.

There are centuries of critique following from Aristotle's work, but it is worth returning to this in this foreword to note the ways in which ethics, education and laws underscore attempts to change or form different habits. In The Nicomachean Ethics, Aristotle (1976: 337) concludes his work with a treatise on 'education in goodness' and posits that this 'is best undertaken by the state: "To obtain a right training for goodness from an early age is hard thing, unless one has been brought up under right laws"”.

The Politics of Researching Multilingually is strongly focused on these habits; on the habits formed in the methods and disciplines of the academy through education, largely in the global north; on a critique of these hegemonic structures and power relations; on the need to decolonise methods and languages. As such we see the work before us grappling with the given habits of western state education and its implications for researchers' multilingual praxis with regard to the politics of languages, which languages are taught, where and why; how translation and interpretation are privileged in certain contexts and not others; the role of sign language; and throughout, widening the lens of the polity to that of global citizenship, and of the non-citizenry in the body of indigenous and displaced peoples.

In The Politics, Aristotle (1981) focuses on the associations of the State, the questions raised by democracy, the rights of 'slave and free', 'gentleman and player', management of the state and of the household ending, in music education as a discipline of body and mind. In his writing in both The Ethics and The Politics, a primacy is placed on education and education as provided by the state. This is well and good, but as the field of multilingual research and its methodologies are subject to critical 
scrutiny and ethical concern, the tense question persists beneath the surface of who is free and who is enslaved.

In The Politics of Researching Multilingually, this tension is explored by giving epistemological and methodological space to a view from southern contexts and therefore, while framed by those long standing conceptualisations, breaking with genealogies back to Aristotle. This choice is both an ethical and a political one. By taking a view from the south, and engaging distinctively with languages of the global south and southern epistemologies (Connell, 2007; Mignolo \& Walsh, 2018; Santos, 2014), the authors in this volume are critically concerned with liberatory linguistic praxis, in documenting it, in analysing its valences and in offering trajectories which may serve both methodologically and politically at the levels of household, community and state. It is for this reason that weight is given in the book to critique of the categories which led to what Gramling (2016) has called 'The Invention of Monolingualism' and to the kinds of work already in play, including translanguaging, which deconstructs, decentres and otherwise privileges languages which are in a parlous situation, or have been devalued as capital and currency.

If decoloniality is the process and project of building, shaping and enabling coloniality's otherwise, interculturality [...] is both a complimentary political, epistemic and existence-based project and an instrument and tool of decoloniality's praxis. (Mignolo \& Walsh, 2018: 57)

Coloniality's other-Wise are present in these pages. Knowledge is present not as an acquisitive production of the postcolony but as a critical, careful curation, held by speakers of many languages, and troubling the questions of liberation and language from many sides. The other-Wise are those who understand and can operate smoothly within the dictates of Empire and the vestiges of Empire, but also have reformed households and civic practices to enable research to be undertaken other-Wise too. This is a political and a Political project. Laws need to be made, and policies of multilinguality brought into the academy which have divested themselves of language departments and of languages. Lessons need to be learned from the constitutions of countries who have enabled indigenous and local languages to act as a medium for education, from Gaelic in Scotland, Welsh in Wales, Te Reo in Aotearoa New Zealand, to the constitution of South Africa with its formal recognition of 11 languages: Afrikaans, English, isiNdebele, isiXhosa, isiZulu, Sepedi, Sesotho, Setswana, siSwati, Tshivenda and Xitsonga. And lessons need to be learned in civic education, for the languages practiced in schools and in universities to be allowed a conviviality (Nyamnjoh, 2019) alongside those used by others.

This book is timely. The debates within it can help navigate the legacies of colonialism and slavery at a time when there is a need for a 
steadiness of method and an approach to politics which listens to that which has been ignored, marginalised, disempowered and which has learned to be intercultural, perhaps one of the most pressing political human values of the day.

Seek and learn to recognise who and what, in the midst of the inferno, are not inferno, then make them endure, give them space. (Calvino, 1979)

\section{References}

Aristotle (1976) The Nicomachean Ethics. London: Penguin.

Aristotle (1981) The Politics. London: Penguin.

Calvino, I. (1979) Invisible Cities. London: Picador.

Connell, R. (2007) Southern Theory: The Global Dynamics of Knowledge in Social Science. London: Allen \& Unwin.

Gramling, D. (2016) The Invention of Monolingualism. New York and London: Bloomsbury.

Holmes, P., Richard, F., Andrews, J. and Mariam, A. (2013) Researching multilingually: New theoretical and methodological directions. International Journal of Applied Linguistics 23, 285-299.

Merleau-Ponty, M. (2002) Phenomenology of Perception. London: Routledge.

Mignolo, W.D. and Walsh, C.E. (2018) On Decoloniality: Concepts, Analytics, Praxis. Durham, NC: Duke University Press.

Nyamnjoh, F.B. (2019) Decolonising the University in Africa. Oxford Research Encyclopedia. Oxford: Oxford University Press.

Santos, B.D.S. (2014) Epistemologies of the South: Justice against Epistemicide. London \& New York: Routledge. 